\title{
Time between milestone events in the Alzheimer's disease amyloid cascade
}

Philip S. Insel, $\mathrm{MS}_{1,2}$, , Michael C. Donohue, $\mathrm{PhD}_{3}$, David Berron, $\mathrm{PhD}_{1}$, Oskar Hansson, MD, PhD 1,4 , Niklas Mattsson-Carlgren, $\mathrm{MD}, \mathrm{PhD}_{1,5,6}$

1Clinical Memory Research Unit, Department of Clinical Sciences Malmö, Lund University, Sweden

${ }_{2}$ Department of Psychiatry, University of California, San Francisco, CA, USA

3Alzheimer's Therapeutic Research Institute, Keck School of Medicine, University of Southern California, San Diego, CA, USA

4Memory Clinic, Skåne University Hospital, Malmö, Sweden

5Department of Neurology, Skåne University Hospital, Lund, Sweden

6Wallenberg Center for Molecular Medicine, Lund University, Lund, Sweden

*Corresponding authors: Philip Insel and Niklas Mattsson-Carlgren, Clinical Memory

Research Unit, Department of Clinical Sciences Malmö, Lund University, Sweden

Phone: (Philip Insel) +1 858652 8480. E-mail: philip.insel@med.lu.se, niklas.mattsson@med.lu.se

Search terms: (1) Alzheimer's disease, (2) $\beta$-amyloid, (3) tau PET, (4) cognition 


\begin{abstract}
Objective: Estimate the time-course of the spread of key pathological markers and the onset of cognitive dysfunction in Alzheimer's disease.

Methods: In a cohort of 336 older adults, ranging in cognitive functioning, we estimated the time of initial changes of $A \beta$, tau, and decreases in cognition with respect to the time of A $\beta$-positivity.

Results: Small effect sizes of change in CSF A $\beta 42$ and regional A $\beta$ PET were estimated to occur several decades before A $\beta$-positivity. Increases in CSF tau occurred 11-12 years before A $\beta$-positivity. Temporoparietal tau PET showed increases 4-5 years before A $\beta$ positivity. Subtle cognitive dysfunction was observed 7-9 years before A $\beta$-positivity. Conclusions: Increases in tau and cognitive dysfunction occur years before the presence of significant $A \beta$. Explicit estimates of the time for these events provide a clearer picture of the time course of the amyloid cascade and identify potential windows for specific treatments.
\end{abstract}




\section{Introduction}

Disconcerting clinical trial results for the treatment of Alzheimer's disease (AD) have led to a shift toward earlier intervention, focusing on the early clinical or presymptomatic phases, when biomarkers are needed to identify the disease. The amyloid cascade (Hardy and Selkoe, 2002) is thought to start with elevated levels of two key amyloids in the brain, $\beta$-amyloid $(\mathrm{A} \beta)$ and tau, and end with severe cognitive and functional impairment (Jack et al., 2010). Growing evidence suggests that an early sign that the cascade has begun is change in cerebrospinal fluid (CSF) $\mathrm{A} \beta$, potentially detectable prior to significant $\mathrm{A} \beta$ deposition in the brain as measured by positron emission tomography (PET) (Palmqvist et al., 2016). This accumulation of A $\beta$ has been suggested to be followed by increases in CSF tau and the spread of tau pathology beyond the temporal lobe (Braak and Braak, 1991; Schöll et al., 2016). The build-up and spread of these two brain pathologies is paralleled by gradual cognitive and functional decline (Zetterberg and Mattsson, 2014).

Previous neuropathological and biomarker data suggest that the overall time course of AD is several decades (Li et al., 2017; Villemagne et al., 2013). In autosomal dominant $\mathrm{AD}$, the estimated years to clinical onset has been used to estimate the timecourse of different biomarkers in AD (Bateman et al., 2012). However, the time-course of the spread of $\mathrm{A} \beta$ and tau and the onset of clinical symptoms in sporadic AD is unknown. With repeated measures of $A \beta$ over time, the level and rate of change with respect to the key initiating AD pathology may offer a measure of disease progression in sporadic AD. With level and change information, the time from the threshold for significant $\mathrm{A} \beta$ pathology can be estimated within individuals, providing the temporal disease 
progression information important for evaluating biomarker trajectories. Without longitudinal information, cross-sectional studies frequently categorize subjects into two groups - those below a threshold for significant pathology and those above, where subjects just below the threshold who will cross over within months are considered pathologically equivalent to subjects who will not cross over for decades. By incorporating longitudinal information, disease progression with respect to $\mathrm{A} \beta$ pathology can be represented to reflect its continuous nature, resulting in a more powerful way to model the relationship between $\mathrm{A} \beta$ and downstream processes.

The aim of this study was to evaluate time-from-A $\beta$-positivity (TFA $\beta+)$ in sporadic AD. Using serial ${ }_{18} \mathrm{~F}-$ florbetapir $(A \beta)$ PET measurements, rates of change of A $\beta$ were estimated and used to calculate the time-from-threshold for each subject. These subject-specific estimates of the proximity to the threshold for $A \beta$-positivity $(A \beta+)$ were then used to model the trajectories and temporal ordering of other key markers in AD including CSF A $\beta 42$, regional A $\beta$ PET, several measures of tau including CSF phosphorylated (P-tau) and total tau (T-tau), regional ${ }_{18} \mathrm{~F}-$ flortaucipir (AV-1451) tau PET, and cognition. Estimates of the time and ordering of these pathophysiological changes may facilitate the design of future prevention trials and identify a window for early treatment. 


\section{Materials and methods}

Standard protocol approvals, registrations, and patient consents.

This study was approved by the Institutional Review Boards of all of the participating institutions. Informed written consent was obtained from all participants at each site.

\section{Data Availability}

All data is publicly available (http://adni.loni.usc.edu/).

\section{Participants}

Data were obtained from the Alzheimer's Disease Neuroimaging Initiative (ADNI) database (http://adni.loni.usc.edu/, www.adni-info.org) on 1/21/2020. An initial analysis was done on all ADNI participants with available $A \beta$ PET data (in $\mathrm{N}=963 \mathrm{CU}$, $\mathrm{A} \beta+\mathrm{MCI}$ and $\mathrm{A} \beta+\mathrm{AD})$, to facilitate the estimation of TFA $\beta+$. The population in the primary analysis only included ADNI participants with measurements of both $\mathrm{A} \beta$ and tau PET. Of these, all cognitively unimpaired $(C U)$, prodromal $A D(A \beta+M C I)$ and $A \beta+A D$ dementia participants were included in the analysis, where $A \beta$-positivity was defined using a previously established threshold (Standardized Uptake Value Ratio, SUVR = 1.10) (Joshi et al., 2012). A $\beta$ - MCI ( $\mathrm{N}=224$, including $\mathrm{A} \beta$ - $\mathrm{CU}$ to MCI progressors) and $\mathrm{A} \beta$ - "AD dementia" subjects $(\mathrm{N}=51$, including $\mathrm{A} \beta$ - MCI to AD dementia progressors; we consider these to be misdiagnosed, because we assume $\mathrm{AD}$ requires $\mathrm{A} \beta+$ ) were not included in the main analysis given our aim to model disease progression over the AD continuum and not other diseases, but visualizations of their biomarker data are included 
for comparison in Figures 2-4 (see Figure legends). Additional description is included in the statistical analysis section.

\section{Cerebrospinal fluid biomarker concentrations}

Cerebrospinal fluid (CSF) samples were collected at baseline by lumbar puncture in a subsample ( $\mathrm{N}=185)$. CSF $\mathrm{A} \beta 42$, total tau ( $\mathrm{T}$-tau) and phosphorylated tau (P-tau) were measured by an xMAP assay (INNOBIA AlzBio3, Ghent, Belgium, Fujirebio), as described previously (Olsson et al., 2005; Shaw et al., 2009).

\section{PET Imaging}

Methods to acquire and process A $\beta$ (18F-florbetapir) PET image data were described previously (Landau et al., 2012). We used an a priori defined threshold for A $\beta$ positivity (SUVR=1.1) (ADNI, 2012; Joshi et al., 2012) applied to the ratio of the average of the four target regions (temporal, cingulate, frontal, and parietal lobes) and the cerebellum, in the estimation of time-from-A $\beta$-positivity, described in detail below. In a second part of the analysis, five A $\beta$ PET ROI outcomes were considered (Landau and Jagust, 2015; Mormino et al., 2009), (1) the temporal lobe (middle and superior temporal lobe), (2) the parietal lobe (precuneus, supramarginal, inferior and superior parietal lobe), (3) the cingulate gyrus (isthmus, posterior, caudal and rostral anterior cingulate), (4) the frontal lobe (pars opercularis, pars triangularis, pars orbitalis, caudal/rostral middle frontal, medial/lateral orbitofrontal, frontal pole, and superior frontal lobe), and (5) a composite of regions thought to be early in accumulating $A \beta$ (precuneus and posterior 
cingulate) (Palmqvist et al., 2017). 18F-florbetapir ROIs were expressed as SUVRs with a cerebellar reference region.

Methods to acquire and process tau (18F-flortaucipir) PET image data were described previously (Maass et al., 2017). Six tau ROI outcomes, corrected for partialvolume, were considered: (1) the medial temporal lobe (MTL) (amygdala, entorhinal and parahippocampal cortex), (2) the lateral temporal lobe (LTL) (inferior/middle/superior temporal lobe, banks of the superior temporal sulcus, transverse temporal lobe, temporal pole), (3) the medial parietal lobe (MPL) (isthmus cingulate, precuneus), (4) the lateral parietal lobe (LPL) (inferior/superior parietal lobe, supramarginal), (5) frontal lobe (pars, orbitofrontal and middle/superior frontal lobe), and (6) the occipital lobe (cuneus, lingual, pericalcarine, and lateral occipital lobe). 18F-flortaucipir ROIs were expressed as SUVRs with an inferior cerebellar grey matter reference region. Full details of PET acquisition and analysis can be found at http://adni.loni.usc.edu/methods/.

\section{Cognition}

Cognitive measures assessed included the Mini-Mental State Examination (MMSE) as a measure of global cognition, and the Preclinical Alzheimer's Cognitive Composite (PACC), as a measure of early AD-related cognitive changes. The PACC comprised the MMSE, the Logical Memory Delayed Word Recall from the Wechsler Memory Scale, the Alzheimer's Disease Assessment Scale—Cognitive Subscale Delayed Word Recall, and the Trail Making Test part B (log transformed) (Donohue et al., 2017, 2014). 


\section{Statistical Analysis}

The aims of these analyses were to evaluate the relationship between the estimated TFA $\beta+$ and CSF, PET, and cognitive responses. Because TFA $\beta+$ was not directly observed, in a first step, linear mixed-effects models were fit to all available longitudinal global A $\beta$ PET SUVR data to estimate subject-specific intercepts and slopes of $A \beta$ pathology. Because $A \beta$ slopes are unlikely to remain constant over long periods of time as subjects move toward and away from the $\mathrm{A} \beta$ threshold, natural splines (Hastie and Tibshirani, 1990) were used to estimate the nonlinear shape of the slopes with respect to baseline $A \beta$, using quantile regression. Rather than modeling the mean $A \beta$ slope with respect to baseline $\mathrm{A} \beta$, quantile regression provides a separate curve for each quantile, allowing the relationship between slope and intercept to differ depending on the location in the distribution of $A \beta$ slope. For each subject, TFA $\beta+$ was estimated by integrating over each subject's quantile curve between the subject's intercept and the threshold for A $\beta$-positivity (PET SUVR = 1.1). For example, for a subject with a baseline SUVR of 1.2 and a slope in the 0.6 quantile, TFA $\beta+$ was taken to be the time it would take to go from $\mathrm{SUVR}=1.1$ to 1.2 , using the slope estimates from the quantile curve. For incremental changes on the $\mathrm{x}$-axis (baseline SUVR), the time required to travel the incremental distance is equal to distance/rate. Using the trapezoid rule (Atkinson, 1989), TFA $\beta+$ is the sum of these incremental times spanning SUVR $=1.1$ to 1.2 . An example of calculating TFA $\beta+$ is given in the top left panel of Figure 1.

To evaluate the accuracy of the TFA $\beta+$ estimates, we compared the observed times of $A \beta+$ to the estimated times of $A \beta+$ values in participants who were $A \beta$ - at baseline and became $A \beta+$ during follow-up. Observed time of $A \beta+$ occurred in the 
interval between the last $A \beta$ - scan and the first $A \beta+$ scan. The observed time was calculated as a weighted average of the two scan times, weighted proportionally toward the scan where the participant was closest to hitting the threshold. Observed and estimated values were compared in $\mathrm{N}=37$ participants who crossed the threshold for $\mathrm{A} \beta+$ and remained $\mathrm{A} \beta+$ throughout follow-up.

Our analyses aim to model participants who are ostensibly on the AD trajectory and had calculable TFA $\beta+$. Therefore, of the 963 participants with A $\beta$ PET, we excluded $\mathrm{N}=16$ participants with negative $\mathrm{A} \beta$ accumulation rates (negative rates were largely driven by one early high A $\beta$ PET measure), we also excluded $\mathrm{N}=6$ participants with low levels of $A \beta$ and accumulation rates such that they were predicted to become $A \beta+$ later than 120 years of age (biomarker data from these subjects are included for visual comparisons in Figures 2-4, see Figure legends). We included subjects where the TFA $\beta+$ metric indicated very early accumulation of $\mathrm{A} \beta$, but for participants estimated to have become $\mathrm{A} \beta+$ before age $40(\mathrm{~N}=24$, median estimated age at $\mathrm{A} \beta+=30$, IQR: 24 to 34), we truncated TFA $\beta+$ to age 40 , based on previously described rates of A $\beta$-positivity in middle age (Jansen et al., 2015).

In the second step, the relationship between TFA $\beta+$ and the responses was modeled using monotone penalized regression splines. Generalized cross-validation was used to tune the smoothing parameter (Wood, 1994). Cognitive responses were covaried for age, gender and education; CSF A $\beta 42$, T-tau, P-tau and PET measures were covaried for age and gender. 
In order to account for the uncertainty across steps 1 and 2, the entire process was repeated in 500 bootstrap samples to estimate $95 \%$ confidence intervals for the association between TFA $\beta+$ and the responses.

Meaningful effect sizes of change of increase in pathology or decrease in cognition with respect to TFA $\beta+$ were estimated. A Cohen's d effect size of 0.2 SD was considered small, 0.5 SD was considered medium, and a $0.8 \mathrm{SD}$ effect was considered large (Cohen, 1988). A 0.2 standard deviation (SD) change from the mean response at the longest times (least pathological) from $\mathrm{A} \beta$-positivity was taken to be the initial point of meaningful change. A $0.5 \mathrm{SD}$ change was also shown as a more substantial effect size of change. We also estimated change, $95 \%$ confidence intervals, and statistical significance of change for each response at TFA $\beta+=0$, the time of A $\beta$-positivity, with bootstrapestimated standard errors.

Baseline associations between demographics and TFA $\beta+$ were assessed using Spearman correlation for age and education and the Wilcoxon rank-sum test for gender. Associations between diagnosis and demographics were assessed using Wilcoxon ranksum test for continuous variables and Fisher's Exact test for categorical variables. All analyses were done in R v3.5.1 (www.r-project.org). 


\section{Results}

\section{Cohort Characteristics}

Two-hundred and twenty-eight CU (128 A $\beta$ - and $100 \mathrm{~A} \beta+), 70 \mathrm{~A} \beta+\mathrm{MCI}$ and 38 $\mathrm{A} \beta+\mathrm{AD}$ participants were included in the analysis. The diagnostic groups varied by mean age (CU-, 70.1 years old [SD=5.8]; $\mathrm{CU}+, 72.9$ years old [SD=6.6]; MCI, 72.0 years old $[\mathrm{SD}=6.9] ; \mathrm{AD}, 74.5$ years old $[\mathrm{SD}=7.2] ; \mathrm{p}<0.001)$. The diagnostic groups varied by sex (CU-, $60.2 \%$ female; CU+, 58.0\% female; MCI, $41.4 \%$ female; AD, $47.4 \%$ female; $\mathrm{p}=0.05)$. The groups differed by mean years of education (CU-, 16.7 years $[\mathrm{SD}=2.4]$; $\mathrm{CU}+, 16.9$ years $[\mathrm{SD}=2.3]$; $\mathrm{MCI}, 16.0$ years $[\mathrm{SD}=2.5]$; $\mathrm{AD}, 15.6$ years $[\mathrm{SD}=2.5]$; $\mathrm{p}=0.007)$. The groups varied by proportion of $A P O E \varepsilon 4+(\mathrm{CU}-, 25.4 \%$; $\mathrm{CU}+, 50.5 \%$; MCI, 60.9\%; AD, 54.3\%; p<0.001).

\section{$A \beta P E T$ and Estimation of TFA $\beta+$}

TFA $\beta+$ was estimated with a median of 3 (range: 1 to 5) A $\beta$ PET scans per participant. The average time between first and last scan was 3.3 years $(\mathrm{SD}=2.9)$ and the average time between scans was 2.2 years $(\mathrm{SD}=0.8)$. Across diagnoses, $\mathrm{TFA} \beta+$ ranged from -35.9 to 47.0 years, where higher (positive) TFA $\beta+$ values indicate more time spent with a significant $\mathrm{A} \beta$ burden. The average TFA $\beta+$ was -9.3 years $(\mathrm{SD}=6.9)$ for $\mathrm{CU}-, 13.9$ years $(\mathrm{SD}=11.2)$ for $\mathrm{CU}+, 21.1$ years (11.7) for MCI, and 25.8 years (11.0) for $\mathrm{AD}$ participants ( $\mathrm{p}<0.001$, comparing $\mathrm{CU}+\mathrm{MCI}$, and AD only). TFA $\beta+$ was highly correlated with observed time of $A \beta+(\rho=0.93$, $p<0.001$, bottom left panel of Figure 1$)$. Higher TFA $\beta+$ was significantly associated with older age $(\rho=0.30, p<0.001)$, lower 
education $(\rho=-0.15, \mathrm{p}=0.01)$ and $A P O E \varepsilon 4$-positivity (mean TFA $\beta+$ in $A P O E \varepsilon 4-=3.0$

$(\mathrm{SD}=16.5)$ years and mean TFA $\beta+$ in $A P O E \varepsilon 4+=13.7(\mathrm{SD}=16.0)$ years, $\mathrm{p}<0.001)$.

TFA $\beta+$ was not associated with sex (mean TFA $\beta+=9.5(\mathrm{SD}=17.4)$ and $6.6(\mathrm{SD}=16.8)$ in

males and females, respectively, $\mathrm{p}=0.13$ ). Within-diagnosis TFA $\beta+$ distributions are

shown on the bottom right panel of Figure 1. Quantile curves of the relationship between

$\mathrm{A} \beta$ intercepts and slopes are also shown in the top right panel of Figure 1, displaying the variation of acceleration of $A \beta$ deposition over different levels of baseline $A \beta$.

\section{Regional A $\beta$ PET}

Five regional ROIs (precuneus + posterior cingulate, frontal lobe, cingulate gyrus, temporal and parietal lobes) are shown plotted against TFA $\beta+$ in Figure 2. All 5 regions were estimated to reach a small, but meaningful (0.2 SD) increase in SUVR between 1617 years before $A \beta$-positivity, i.e. TFA $\beta+=0$. Effect sizes over the span of TFA $\beta+$ are shown in Figure 2. At TFA $\beta+=0$, all regions showed large, significant increases in SUVR $(\triangle \operatorname{SUVR} \geq 0.13, \mathrm{p} \leq 0.01)$ with the precuneus + posterior cingulate composite showing the largest increase $(\triangle \mathrm{SUVR}=0.19, \mathrm{p}<0.01)$ and the temporal lobe showing the smallest $(\triangle \mathrm{SUVR}=0.13, \mathrm{p}<0.01)$. Effect sizes for all regions were large $(>1)$ by the time of $A \beta+$. Table 1 summarizes the values of the responses at the longest times before $\mathrm{A} \beta+$, i.e. the least pathological TFA $\beta+$. Table 1 also shows the value and change of each response at the time of $\mathrm{A} \beta$-positivity $(\mathrm{TFA} \beta+=0), \mathrm{p}$-value and corresponding $95 \%$ confidence interval, the effect size of change of each response, and the 0.2 SD change point with respect to TFA $\beta+$. 
CSF

CSF responses are plotted against TFA $\beta+$ in Figure 3. A 0.2 SD drop in CSF $\mathrm{A} \beta 42$ was estimated to occur 35 years before $\mathrm{A} \beta$-positivity $(\mathrm{TFA} \beta+=-35)$. At TFA $\beta+=$ $0, \mathrm{CSF} A \beta 42$ showed a very large effect size $(\triangle \mathrm{A} \beta 42=-74 \mathrm{ng} / \mathrm{L}, \mathrm{p}<0.01$, effect size $=-$ 2.17). At TFA $\beta+=-2$, or two years before $A \beta$-positivity, the population curve passes through a previously published CSF A $\beta 42$ threshold for A $\beta$-positivity (192 ng/L) (Shaw et al., 2009).

A 0.2 SD increase in CSF T-tau and P-tau was estimated to occur 11-12 years before the time of $A \beta$-positivity (TFA $\beta+=-12$ and -11 , respectively). At TFA $\beta+=0$, significant increases of medium effect size of T-tau $(\Delta \mathrm{T}-\mathrm{tau}=25 \mathrm{ng} / \mathrm{L}, \mathrm{p}=0.01$, effect size $=0.59)$ and P-tau $(\Delta \mathrm{P}-\operatorname{tau}=14 \mathrm{ng} / \mathrm{L}, \mathrm{p}=0.02$, effect size $=0.55)$ were observed.

\section{Tau PET}

Six regional ROIs (MTL, LTL, MPL, LPL, frontal and occipital lobes) are shown plotted against TFA $\beta+$ in Figure 4. Five of the six regions were estimated to reach a 0.2 SD increase in SUVR 3-5 years before A $\beta$-positivity, with the occipital lobe reaching a 0.2 SD increase one year after A $\beta$-positivity. Effect sizes over the span of TFA $\beta+$ are shown in Figure 4. At TFA $\beta+=0$, four regions (MTL, LTL, MPL, LPL) showed significant small increases in $\operatorname{SUVR}(\triangle \mathrm{SUVR} \geq 0.12, \mathrm{p} \leq 0.05)$ with the MTL showing the largest effect size (0.35). The frontal and occipital lobes did not increase significantly by TFA $\beta+=0(\Delta$ SUVR $=0.09,0.07$, respectively, $\mathrm{p}=0.13)$. Estimates are summarized in

\section{Table 1.}


bioRxiv preprint doi: https://doi.org/10.1101/2020.05.18.103226; this version posted May 21, 2020. The copyright holder for this preprint (which

was not certified by peer review) is the author/funder, who has granted bioRxiv a license to display the preprint in perpetuity. It is made available under aCC-BY 4.0 International license.

\section{Cognition}

Cognitive measures are shown in Figure 5. The MMSE showed a 0.2 SD drop nine years before $A \beta$-positivity, followed by the PACC seven years before A $\beta$-positivity. Neither measure decreased significantly by the time of $A \beta$-positivity, although the PACC was borderline $(\triangle \mathrm{MMSE}=-0.80, \mathrm{p}=0.17$, effect size $=-0.34 ; \triangle \mathrm{PACC}=-0.61, \mathrm{p}=0.07$ effect size=-0.39). Summary curves and 0.2 SD change points are shown in Figure 6. 


\section{Discussion}

Several biological processes develop over time in sporadic AD, including accumulation of $A \beta$ and tau across wide areas of the brain, as well as cognitive decline. Based on the amyloid cascade hypothesis, a relevant overarching time scale of the disease processes could be based on the development of $A \beta$ pathology (Koscik et al., 2020). We have therefore integrated $\mathrm{A} \beta$ PET level and rate of change information to place each individual on a pathological timeline. This timeline can then be used to estimate the time of downstream events in the amyloid cascade. We estimated several major milestone events of $A D$ progression including a small drop in CSF $A \beta 4235$ years before $A \beta$ positivity and a small increase in regional A $\beta$ PET deposition 17 years before $A \beta$ positivity. Using the biomarkers tested here, the first changes in CSF A $\beta 42$ may define the onset of AD. Small increases in tau pathology were estimated to occur 11-12 years before A $\beta$-positivity, as measured by CSF and 5 years before, as measured by PET. More substantial and statistically significant increases in CSF as well as temporoparietal tau PET were detected by the time of A $\beta$-positivity. Small effects of cognitive dysfunction occurred 7-9 years before A $\beta$-positivity, coinciding with previous reports (Insel et al., 2017). These findings provide a general time scale for initial changes in sporadic AD, which may inform clinical trials aimed at specific stages of the disease.

A 0.2 SD difference, a small, but meaningful increase in levels of CSF tau and temporoparietal lobe tau are observed years before the current threshold for A $\beta$ positivity. In the context of secondary prevention trials where $A \beta$-positivity at current thresholds is required for study inclusion, tau levels in these participants would already 
have been increasing for several years, likely more. The finding that temporoparietal tau starts to increase prior to other regions is in accordance with $18 \mathrm{~F}$-flortaucipir studies on other populations. Cross-sectional studies showed early tau deposition in cognitively healthy elderly (with or without significant $\mathrm{A} \beta$ pathology) in temporal and medial parietal regions, most dominant in entorhinal and parahippocampal cortex, the amygdala and inferior temporal cortex. Longitudinal studies further suggest that cognitively healthy elderly accumulate tau in the medial temporal and medial parietal lobe, while (A $\beta$ positive) $\mathrm{AD}$ dementia patients increased in tau primarily in the frontal lobe (Harrison et al., 2018). The spread of tau beyond the MTL to the parietal lobe and other regions may be a critical milestone in the progression of AD. The early changes observed in the MPL in this study coincide with a recent report of the earliest tau deposition found in medial parietal regions (precuneus and isthmus cingulate) in autosomal dominant AD (Gordon et al., 2019). Considering that a 0.2 SD increase in MPL tau can potentially be detected several years before A $\beta$-positivity (Figure 4), these data support the use of primary prevention trials against $A \beta$ where treatment is initiated years before the current threshold for $A \beta$-positivity, if treatment efficacy relies on early intervention, prior to the development of tau pathology.

The initial descent in cognitive performance is estimated to occur 7-9 years before becoming $A \beta+$ (Figure 5). Reduced cognitive performance has repeatedly been shown to be associated with elevated levels of A $\beta$ (Baker et al., 2017; Donohue et al., 2017; Insel et al., 2017, 2016), even within the subthreshold range (Landau et al., 2018), in cognitively unimpaired individuals. The result that CSF tau measures started to change between regional $A \beta$ and cognition in this study is in accordance with the theory that 
cognitive impairment in $\mathrm{AD}$ is caused primarily by tau pathology. This is also in line with other recent studies which show that cognitive impairment is more strongly related to accumulation of tau than to $\mathrm{A} \beta$ (Ossenkoppele et al., 2019), and that both tau and $\mathrm{A} \beta$ appear necessary for cognitive decline (Sperling et al., 2019). The ordering of the responses coincides with the magnitude of the effect sizes at the time of $A \beta$-positivity (Table 1), suggesting that initial changes in the responses continue to change in parallel through to the time of $\mathrm{A} \beta$-positivity, without any major differences in acceleration.

In their 2018 draft guidance, the FDA indicated that because it is highly desirable to intervene as early as possible in $\mathrm{AD}$, it follows that patients with characteristic pathophysiologic changes of AD but no subjective complaint, functional impairment, or detectable abnormalities on sensitive neuropsychological measures are an important target for clinical trials (Food and Drug Administration, 2018). If the spread of tau to the lateral temporal and parietal lobes becomes a defining characteristic of pathophysiological change in $\mathrm{AD}$, the window to intervene as early as possible may shift to years before the current threshold for $A \beta$-positivity. It is possible that early accelerations of tau may have contributed to recent failures of anti-A $\beta$ treatments in phase III clinical trials on A $\beta$-positive patients (Egan et al., 2018; Honig et al., 2018). Although selecting subjects that are $\mathrm{A} \beta$-positive ensures that only AD patients are included in trials, the use of conservative thresholds to define $A \beta$-positivity may bias trial populations toward individuals where tau pathology has already accumulated, causing downstream injuries independent of $A \beta$, reducing the efficacy of anti-A $\beta$ treatments.

This study has several limitations. Tau PET data were available for only a subsample of the data, limiting comparisons to a small cross-section of the full ADNI 
data set. More data, especially longitudinal data in participants in the earliest stages of $\mathrm{A} \beta$ changes, will be required for more precise change point estimates. These analyses lack the power and precision to place the temporal and parietal tau regions in a particular order with confidence, but instead demonstrate that temporoparietal tau increases years before $\mathrm{A} \beta$-positivity. The ADNI CU, MCI and AD cohorts are also age matched. The AD patients, on average, have dementia by age 75 , while the participants in the CU cohort who may eventually develop AD, are unlikely to do so for many years, possibly decades. By design, these cohorts with age matched groups are therefore on systematically different disease trajectories with respect to age. If earlier onset is associated with a more aggressive form of the disease, then the $\mathrm{AD}$ cohort may have the most aggressive form while the CU cohort, the least aggressive. If the developing $A \beta$ pathology in the ADNI CU- cohort represents a less aggressive disease process compared with a more typical AD process, the estimates reported here could be conservative and biased toward later time estimates for downstream events. The ADNI MCI cohort may represent a more typical trajectory with respect to downstream events along the $\mathrm{A} \beta$ pathological timeline. These differences in disease trajectories are apparent from the cohort estimates in Figures 2-5. Additionally, the change point estimates are influenced by both biological variation and measurement error, which varies from marker to marker. Change points in measures with high variability in the "normal" range and excess measurement error may require additional biological change to detect, despite an earlier, real increase in pathology. ADNI participants are highly educated on average, reducing generalizability to some degree. The associations between increasing $\mathrm{A} \beta$ pathology and downstream changes, including increased tau pathology reported here do not imply causality. It remains 
unknown whether and to what degree downstream pathological changes can be directly attributed to the accumulation of $\mathrm{A} \beta$. Only studies with experimental interventions against $A \beta$-pathology, with clear verification of target engagement, can be used to show causal relationships between $\mathrm{A} \beta$-deposition and putative downstream events.

Longitudinal information is required to evaluate how quickly an individual's pathophysiological changes are occurring and to accurately characterize their disease trajectory. Analyses limited to a cross-sectional evaluation of $A \beta$ status are naïve to the time spent with a significant $\mathrm{A} \beta$ burden. Incorporating longitudinal information facilitates the estimation of the time-course of downstream events such as the spread of tau and the onset of subtle cognitive dysfunction. As the technology to measure AD pathology becomes more cost effective and noninvasive, such as plasma measures of $\mathrm{A} \beta$ or tau (Janelidze et al., 2020; Mielke et al., 2018; Palmqvist et al., 2019; Schindler et al., 2019), longitudinal evaluations in the context of trial-ready cohorts may greatly improve early diagnosis and expedite the execution of clinical trials in early AD. 


\section{Acknowledgements}

Data collection and sharing for this project was funded by the Alzheimer's Disease Neuroimaging Initiative (ADNI) (National Institutes of Health Grant U01 AG024904).

ADNI is funded by the National Institute on Aging, the National Institute of Biomedical Imaging and Bioengineering, and through generous contributions from the following:

Alzheimer's Association; Alzheimer's Drug Discovery Foundation; BioClinica, Inc.;

Biogen Idec Inc.; Bristol-Myers Squibb Company; Eisai Inc.; Elan Pharmaceuticals, Inc.;

Eli Lilly and Company; F. Hoffmann-La Roche Ltd and its affiliated company

Genentech, Inc.; GE Healthcare; Innogenetics, N.V.; IXICO Ltd.; Janssen Alzheimer

Immunotherapy Research \& Development, LLC.; Johnson \& Johnson Pharmaceutical

Research \& Development LLC.; Medpace, Inc.; Merck \& Co., Inc.; Meso Scale

Diagnostics, LLC.; NeuroRx Research; Novartis Pharmaceuticals Corporation; Pfizer

Inc.; Piramal Imaging; Servier; Synarc Inc.; and Takeda Pharmaceutical Company. The

Canadian Institutes of Health Research is providing funds to support ADNI clinical sites

in Canada. Private sector contributions are facilitated by the Foundation for the National

Institutes of Health (www.fnih.org). The grantee organization is the Northern California

Institute for Research and Education, and the study is coordinated by the Alzheimer's

Therapeutic Research Institute at the University of Southern California, San Diego.

ADNI data are disseminated by the Laboratory for Neuro Imaging at the University of

Southern California. Data used in preparation of this article were obtained from the

Alzheimer's Disease Neuroimaging Initiative (ADNI) database (adni.loni.usc.edu). As

such, the investigators within the ADNI contributed to the design and implementation of

ADNI and/or provided data but did not participate in analysis or writing of this report. A 
complete listing of ADNI investigators can be found at: http://adni.loni.usc.edu/wpcontent/uploads/how_to_apply/ADNI_Acknowledgement_List.pdf.

This research was also supported by The Wallenberg Center for Molecular Medicine at Lund University, the Knut and Alice Wallenberg foundation, The Medical Faculty at Lund University, Region Skåne, the Skåne University Hospital Foundation, the Swedish Research Council, the Swedish Alzheimer Foundation, the Swedish Brain Foundation, the Swedish Medical Association, the Konung Gustaf V:s och Drottning Victorias Frimurarestiftelse, the Greta and Johan Kock Foundation, the Thelma Zoega Foundation, the Gyllenstiernska Krapperupsstiftelsen, the Magnus Bergwall Foundation, the Bundy Academy, the Marianne and Marcus Wallenberg foundation, and the Strategic Research Area MultiPark (Multidisciplinary Research in Parkinson's disease) at Lund University. The funding sources had no role in the design and conduct of the study, in the collection, analysis, interpretation of the data or in the preparation, review or approval of the manuscript. 
bioRxiv preprint doi: https://doi.org/10.1101/2020.05.18.103226; this version posted May 21, 2020. The copyright holder for this preprint (which

was not certified by peer review) is the author/funder, who has granted bioRxiv a license to display the preprint in perpetuity. It is made available under aCC-BY 4.0 International license.

\section{Competing Interests}

Mr. Insel, Dr. Berron and Dr. Donohue report no competing interests.

Dr. Mattsson-Carlgren has been a consultant for ADNI.

Dr. Hansson has acquired research support (for the institution) from Roche, GE

Healthcare, Biogen, AVID Radiopharmaceuticals and Euroimmun. In the past 2 years, he has received consultancy/speaker fees (paid to the institution) from Biogen and Roche. 


\section{References}

ADNI. 2012. ADNI Commonly Used Tables. https://adni.loni.usc.edu/wpcontent/uploads/2012/08/instruction-about-data.pdf

Atkinson KE. 1989. An Introduction to Numerical Analysis, 2nd ed. New York: John Wiley \& Sons.

Baker JE, Lim YY, Pietrzak RH, Hassenstab J, Snyder PJ, Masters CL, Maruff P. 2017. Cognitive impairment and decline in cognitively normal older adults with high amyloid- $\beta$ : A meta-analysis. Alzheimer's Dement Diagnosis, Assess Dis Monit 6:108-121. doi:10.1016/j.dadm.2016.09.002

Bateman RJ, Xiong C, Benzinger TLS, Fagan AM, Goate A, Fox NC, Marcus DS, Cairns NJ, Xie X, Blazey TM, Holtzman DM, Santacruz A, Buckles V, Oliver A, Moulder K, Aisen PS, Ghetti B, Klunk WE, McDade E, Martins RN, Masters CL, Mayeux R, Ringman JM, Rossor MN, Schofield PR, Sperling RA, Salloway S, Morris JC. 2012. Clinical and biomarker changes in dominantly inherited Alzheimer's disease. $N$ Engl J Med 367:795-804. doi:10.1056/NEJMoa1202753

Braak H, Braak E. 1991. Acta H' pathologica Neuropathological stageing of Alzheimerrelated changes. Acta Neuropathol 82:239-259. doi:10.1007/BF00308809

Cohen J. 1988. Statistical Power Analysis for the Behavioral Sciences, 2nd ed. New York: Lawrence Earlbaum Associates.

Donohue MC, Sperling RA, Petersen R, Sun C-K, Weiner MW, Aisen PS. 2017. Association Between Elevated Brain Amyloid and Subsequent Cognitive Decline Among Cognitively Normal Persons. JAMA 317:2305-2316. doi:10.1001/jama.2017.6669

Donohue MC, Sperling RA, Salmon DP, Rentz DM, Raman R, Thomas RG, Weiner M, Aisen PS, Australian Imaging, Biomarkers, and Lifestyle Flagship Study of Ageing, Alzheimer's Disease Neuroimaging Initiative, Alzheimer's Disease Cooperative Study. 2014. The preclinical Alzheimer cognitive composite: measuring amyloidrelated decline. JAMA Neurol 71:961-70. doi:10.1001/jamaneurol.2014.803

Egan MF, Kost J, Tariot PN, Aisen PS, Cummings JL, Vellas B, Furtek C, Harper Mozley L, Mahoney E, Vandenberghe R, Mukai Y, Voss T, Mo Y, Sur C, 
Michelson D. 2018. Randomized Trial of Verubecestat for Mild-to-Moderate Alzheimer's Disease. N Engl J Med 378:1691-1703. doi:10.1056/nejmoa1706441

Food and Drug Administration. 2018. Early Alzheimer's disease: developing drugs for treatment guidance for industry.

Gordon BA, Blazey TM, Christensen J, Dincer A, Flores S, Keefe S, Chen C, Su Y, Mcdade EM, Wang G, Li Y, Hassenstab J, Aschenbrenner A, Hornbeck R, Jack CR, Ances BM, Berman SB, Brosch JR, Galasko D, Gauthier S, Lah JJ, Masellis M, Dyck CH Van, Mintun MA, Klein G, Ristic S, Cairns NJ, Marcus DS, Xiong C, Holtzman DM, Raichle ME, Morris JC, Bateman RJ, Benzinger TLS. 2019. Tau PET in autosomal dominant Alzheimer's disease: relationship with cognition, dementia and other biomarkers. Brain A J Neurol 142:1063-1076. doi:10.1093/brain/awz019 BRAIN

Hardy J, Selkoe DJ. 2002. The amyloid hypothesis of Alzheimer's disease: progress and problems on the road to therapeutics. Science 297:353-356.

doi:10.1126/science.1072994

Harrison TM, La Joie R, Maass A, Baker SL, Swinnerton K, Fenton L, Mellinger TJ, Edwards L, Pham J, Miller BL, Rabinovici GD, Jagust WJ. 2018. Longitudinal tau accumulation and atrophy in aging and alzheimer disease. Ann Neurol 85:229-240. doi:10.1002/ana.25406

Hastie TJ, Tibshirani RJ. 1990. Generalized Additive Models. Monogr Stat Appl Probab. doi:10.1016/j.csda.2010.05.004

Honig LS, Vellas B, Woodward M, Boada M, Bullock R, Borrie M, Hager K, Andreasen N, Scarpini E, Liu-Seifert H, Case M, Dean RA, Hake A, Sundell K, Poole Hoffmann V, Carlson C, Khanna R, Mintun M, DeMattos R, Selzler KJ, Siemers E. 2018. Trial of Solanezumab for Mild Dementia Due to Alzheimer's Disease. N Engl J Med 378:321-330. doi:10.1056/NEJMoa1705971

Insel PS, Donohue MC, Mackin RS, Aisen PS, Hansson O, Weiner MW, Mattsson N. 2016. Cognitive and functional changes associated with $A \beta$ pathology and the progression to mild cognitive impairment. Neurobiol Aging 48:172-181. doi:10.1016/j.neurobiolaging.2016.08.017

Insel PS, Ossenkoppele R, Gessert D, Jagust W, Landau S, Hansson O, Weiner MW, 
Mattsson N. 2017. Time to amyloid positivity and preclinical changes in brain metabolism, atrophy, and cognition: Evidence for emerging amyloid pathology in alzheimer's disease. Front Neurosci 11:1-9. doi:10.3389/fnins.2017.00281

Jack CR, Knopman DS, Jagust WJ, Shaw LM, Aisen PS, Weiner MW, Petersen RC, Trojanowski JQ. 2010. Hypothetical model of dynamic biomarkers of the Alzheimer's pathological cascade. Lancet Neurol 9:119-128. doi:10.1016/S14744422(09)70299-6

Janelidze S, Mattsson N, Palmqvist S, Smith R, Beach TG, Serrano GE, Chai X, Proctor NK, Eichenlaub U, Zetterberg H, Blennow K, Reiman EM, Stomrud E, Dage JL, Hansson O. 2020. Plasma P-tau181 in Alzheimer's disease: relationship to other biomarkers, differential diagnosis, and longitudinal progression to Alzheimer's dementia. Nat Med 26:379-386. doi:10.1038/s41591-020-0755-1

Jansen WJ, Ossenkoppele R, Knol DL, Tijms BM, Scheltens P, Verhey FRJ, Visser PJ, Aalten P, Aarsland D, Alcolea D, Alexander M, Almdahl IS, Arnold SE, Baldeiras I, Barthel H, van Berckel BNM, Bibeau K, Blennow K, Brooks DJ, van Buchem MA, Camus V, Cavedo E, Chen K, Chetelat G, Cohen AD, Drzezga A, Engelborghs S, Fagan AM, Fladby T, Fleisher AS, van der Flier WM, Ford L, Förster S, Fortea J, Foskett N, Frederiksen KS, Freund-Levi Y, Frisoni GB, Froelich L, Gabryelewicz T, Gill KD, Gkatzima O, Gómez-Tortosa E, Gordon MF, Grimmer T, Hampel H, Hausner L, Hellwig S, Herukka S-K, Hildebrandt H, Ishihara L, Ivanoiu A, Jagust WJ, Johannsen P, Kandimalla R, Kapaki E, Klimkowicz-Mrowiec A, Klunk WE, Köhler S, Koglin N, Kornhuber J, Kramberger MG, Van Laere K, Landau SM, Lee DY, de Leon M, Lisetti V, Lleó A, Madsen K, Maier W, Marcusson J, Mattsson N, de Mendonça A, Meulenbroek O, Meyer PT, Mintun MA, Mok V, Molinuevo JL, Møllergård HM, Morris JC, Mroczko B, Van der Mussele S, Na DL, Newberg A, Nordberg A, Nordlund A, Novak GP, Paraskevas GP, Parnetti L, Perera G, Peters O, Popp J, Prabhakar S, Rabinovici GD, Ramakers IHGB, Rami L, Resende de Oliveira C, Rinne JO, Rodrigue KM, Rodríguez-Rodríguez E, Roe CM, Rot U, Rowe CC, Rüther E, Sabri O, Sanchez-Juan P, Santana I, Sarazin M, Schröder J, Schütte C, Seo SW, Soetewey F, Soininen H, Spiru L, Struyfs H, Teunissen CE, Tsolaki M, Vandenberghe R, Verbeek MM, Villemagne VL, Vos SJB, van Waalwijk van Doorn 
LJC, Waldemar G, Wallin A, Wallin ÅK, Wiltfang J, Wolk DA, Zboch M, Zetterberg H. 2015. Prevalence of Cerebral Amyloid Pathology in Persons Without Dementia: A Meta-analysis. Jama 313:1924-1938. doi:10.1001/jama.2015.4668 Joshi AD, Pontecorvo MJ, Clark CM, Carpenter AP, Jennings DL, Mintun MA, Adler LP, Burns JD, Saha K, Sadowsky CH, Kovnat KD, Lowrey MJ, Arora A, Seibyl JP, Skovronsky DM. 2012. Performance Characteristics of Amyloid PET with Florbetapir F 18 in Patients with Alzheimer's Disease and Cognitively Normal Subjects. J Nucl Med 53:378-384. doi:10.2967/jnumed.111.090340

Koscik RL, Betthauser TJ, Jonaitis EM, Allison SL, Clark LR, Hermann BP, Cody KA, Engle JW, Barnhart TE, Stone CK, Chin NA, Carlsson CM, Asthana S, Christian BT, Johnson SC. 2020. Amyloid duration is associated with preclinical cognitive decline and tau PET. Alzheimer's Dement Diagnosis, Assess Dis Monit 12:1-10. doi:10.1002/dad2.12007

Landau S, Jagust W. 2015. Florbetapir processing methods. https://adni.bitbucket.io/reference/docs/UCBERKELEYAV45/ADNI_AV45_Metho ds_JagustLab_06.25.15.pdf

Landau SM, Horng A, Jagust WJ. 2018. Memory decline accompanies subthreshold amyloid accumulation. Neurology 10.1212/WNL.0000000000005354. doi:10.1212/WNL.0000000000005354

Landau SM, Mintun MA, Joshi AD, Koeppe RA, Petersen RC, Aisen PS, Weiner MW, Jagust WJ. 2012. Amyloid deposition, hypometabolism, and longitudinal cognitive decline. Ann Neurol 72:578-586. doi:10.1002/ana.23650

Li D, Iddi S, Thompson WK, Donohue MC. 2017. Bayesian latent time joint mixed effect models for multicohort longitudinal data. Stat Methods Med Res 1-11. doi:10.1177/0962280217737566

Maass A, Landau S, Horng A, Lockhart SN, Rabinovici GD, Jagust WJ, Baker SL, La Joie R. 2017. Comparison of multiple tau-PET measures as biomarkers in aging and Alzheimer's disease. Neuroimage 157:448-463. doi:10.1016/j.neuroimage.2017.05.058

Mielke MM, Hagen CE, Xu J, Chai X, Vemuri P, Lowe VJ, Airey DC, Knopman DS, Roberts RO, Machulda MM, Jack CR, Petersen RC, Dage JL. 2018. Plasma 
phospho-tau181 increases with Alzheimer's disease clinical severity and is associated with tau- and amyloid-positron emission tomography. Alzheimer's Dement 14:989-997. doi:10.1016/j.jalz.2018.02.013

Mormino EC, Kluth JT, Madison CM, Rabinovici GD, Baker SL, Miller BL, Koeppe RA, Mathis CA, Weiner MW, Jagust WJ. 2009. Episodic memory loss is related to hippocampal-mediated $\beta$-amyloid deposition in elderly subjects. Brain 132:1310 1323. doi:10.1093/brain/awn320

Olsson A, Vanderstichele H, Andreasen N, De Meyer G, Wallin A, Holmberg B, Rosengren L, Vanmechelen E, Blennow K. 2005. Simultaneous measurement of $\beta$ amyloid(1-42), total Tau, and phosphorylated Tau (Thr181) in cerebrospinal fluid by the xMAP technology. Clin Chem 51:336-345. doi:10.1373/clinchem.2004.039347

Ossenkoppele R, Smith R, Ohlsson T, Strandberg O, Mattsson N, Insel PS, Palmqvist S, Hansson O. 2019. Associations between tau, $A \beta$, and cortical thickness with cognition in Alzheimer disease. Neurology 92:e601-e612. doi:10.1212/wnl.0000000000006875

Palmqvist S, Janelidze S, Stomrud E, Zetterberg H, Karl J, Zink K, Bittner T, Mattsson N, Eichenlaub U, Blennow K, Hansson O. 2019. Performance of Fully Automated Plasma Assays as Screening Tests for Alzheimer Disease-Related $\beta$-Amyloid Status. JAMA Neurol 76:1060-1069. doi:10.1001/jamaneurol.2019.1632

Palmqvist S, Mattsson N, Hansson O. 2016. Cerebrospinal fluid analysis detects cerebral amyloid-?? accumulation earlier than positron emission tomography. Brain

139:1226-1236. doi:10.1093/brain/aww015

Palmqvist S, Schöll M, Strandberg O, Mattsson N, Stomrud E, Zetterberg H, Blennow K, Landau S, Jagust W, Hansson O. 2017. Earliest accumulation of $\beta$-amyloid occurs within the default-mode network and concurrently affects brain connectivity. Nat Commun 8. doi:10.1038/s41467-017-01150-X

Schindler SE, Bollinger JG, Ovod V, Mawuenyega KG, Li Y, Gordon BA, Holtzman DM, Morris JC, Benzinger TLS, Xiong C, Fagan AM, Bateman RJ. 2019. Highprecision plasma $\beta$-amyloid 42/40 predicts current and future brain amyloidosis. Neurology 10.1212/WNL.0000000000008081. doi:10.1212/wnl.0000000000008081 Schöll M, Lockhart SN, Schonhaut DR, O’Neil JP, Janabi M, Ossenkoppele R, Baker SL, 
Vogel JW, Faria J, Schwimmer HD, Rabinovici GD, Jagust WJ. 2016. PET Imaging of Tau Deposition in the Aging Human Brain. Neuron 89:971-982. doi:10.1016/j.neuron.2016.01.028

Shaw LM, Vanderstichele H, Knapik-Czajka M, Clark CM, Aisen PS, Petersen RC, Blennow K, Soares H, Simon A, Lewczuk P, Dean R, Siemers E, Potter W, Lee VM, Trojanowski JQ. 2009. Cerebrospinal fluid biomarker signature in Alzheimer's disease neuroimaging initiative subjects. Ann Neurol 65:403-13. doi:10.1002/ana.21610

Sperling RA, Mormino EC, Schultz AP, Betensky RA, Papp K V., Amariglio RE, Hanseeuw BJ, Buckley R, Chhatwal J, Hedden T, Marshall GA, Quiroz YT, Donovan NJ, Jackson J, Gatchel JR, Rabin JS, Jacobs H, Yang HS, Properzi M, Kirn DR, Rentz DM, Johnson KA. 2019. The impact of amyloid-beta and tau on prospective cognitive decline in older individuals. Ann Neurol 85:181-193. doi:10.1002/ana.25395

Villemagne VL, Burnham S, Bourgeat P, Brown B, Ellis KA, Salvado O, Szoeke C, Macaulay SL, Martins R, Maruff P, Ames D, Rowe CC, Masters CL. 2013. Amyloid $\beta$ deposition, neurodegeneration, and cognitive decline in sporadic Alzheimer's disease: A prospective cohort study. Lancet Neurol 12:357-367. doi:10.1016/S14744422(13)70044-9

Wood SN. 1994. Monotonic smoothing splines fitted by cross validation. SIAM 15:11261133. doi:10.1137/0915069

Zetterberg H, Mattsson N. 2014. Understanding the cause of sporadic Alzheimer's disease. Expert Rev Neurother 14:621-630. doi:10.1586/14737175.2014.915740 


\section{Figures}

\section{Figure 1. Observed vs. Estimated TFA $\beta+$, Quantile Regression Curves and TFA $\beta+$}

\section{Densities}

Top left panel: an example of how TFA $\beta+$ is estimated. Here we have a participant with an estimated intercept of SUVR $=1.00$ and an accumulation rate (slope) of 0.005

SUVR/year. We want to calculate how long it will take for them to reach the 1.10 threshold. A slope of 0.005 SUVR/year puts this participant on the 0.20 quantile $(20 \%$ percentile) curve. We know this participant must accumulate 0.10 SUVR to reach the threshold and we will assume they will continue to have an accumulation rate in the 0.20 quantile. Partitioning the curve into segments from SUVR $=1.00$ to 1.10 and using the formula time $=$ distance/rate, the time to cross each segment is calculated and summed. In the figure, only two segments are shown, but in the actual calculation, the curve is partitioned into a large number of segments. Assuming a linear rate increase within each segment (shown in the dashed black line along the red quantile curve), the time to travel the distance in the $1_{\text {st }}$ segment, from SUVR 1.00 to 1.05 is given by, time $1=\mathrm{d}_{1} / \mathrm{rate}_{1}$, where $\mathrm{d}_{1}$ is 0.05 and rate 1 is the average rate in segment 1 , which is $1 / 2\left(\mathrm{~h}_{0}+\mathrm{h}_{1}\right)$, as shown in the panel. A similar calculation is done for segment 2 and the results are summed to give $\mathrm{TFA} \beta+=15$

Top right panel: quantile regression curves of A $\beta$ PET slopes plotted against intercepts.

Curves for several selected quantiles $(0.01,0.10, \ldots, 0.99)$ are shown in red.

Bottom left panel: observed time of $A \beta+$ plotted against estimated time of $A \beta+$. 
bioRxiv preprint doi: https://doi.org/10.1101/2020.05.18.103226; this version posted May 21, 2020. The copyright holder for this preprint (which

was not certified by peer review) is the author/funder, who has granted bioRxiv a license to display the preprint in perpetuity. It is made available under aCC-BY 4.0 International license.

Bottom right panel: distributions of TFA $\beta+$ for each group, $A \beta-C U(C U-), A \beta+C U$

(CU+), MCI, and AD are shown.
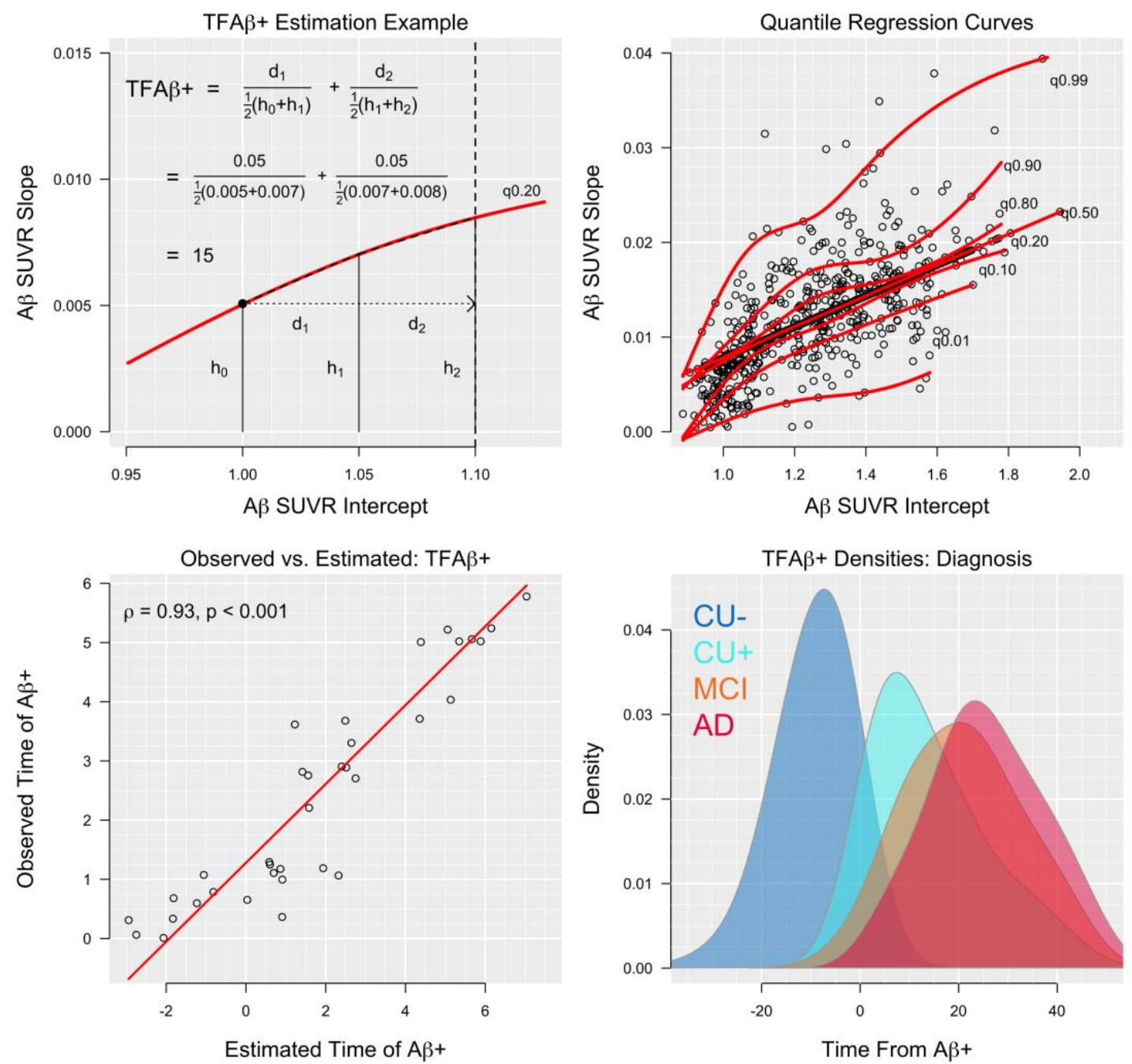


\section{Figure 2. Regional A $\beta$ PET}

A $\beta$ PET ROIs are plotted against TFA $\beta+$. Effect sizes, depicting change points are shown as vertical dashed (0.2 SD, initial change) and solid (0.5 SD) lines. Regression curves (red) and corresponding 95\% CIs (shaded grey) are shown. Mean values of the response are plotted against mean TFA $\beta+$ for each of the four diagnosis groups (large symbols). The 0.95 quantile (approximately $1.65 \mathrm{SD}$ if normally distributed) of the response for the CU- group is also shown (short/long dashed line). The 0.95 quantile (or 0.05 quantile for responses where low values are worse) of the biomarkers in CU-, provided for all responses to facilitate comparisons of when (in terms of TFA $\beta+$ ) the average level of each response is no longer in the normal range. The boxplots to the left of each figure show the biomarker distribution in subjects that was determined to not be on the AD trajectory (including subjects where the model estimated them to become $A \beta+$ at over 120 years of age). Effect sizes of $A \beta$ increase are shown in the bottom panel at TFA $\beta+=$ $-20,-10,0,10$, and 20 years. 
bioRxiv preprint doi: https://doi.org/10.1101/2020.05.18.103226; this version posted May 21, 2020. The copyright holder for this preprint (which

was not certified by peer review) is the author/funder, who has granted bioRxiv a license to display the preprint in perpetuity. It is made available under aCC-BY 4.0 International license.
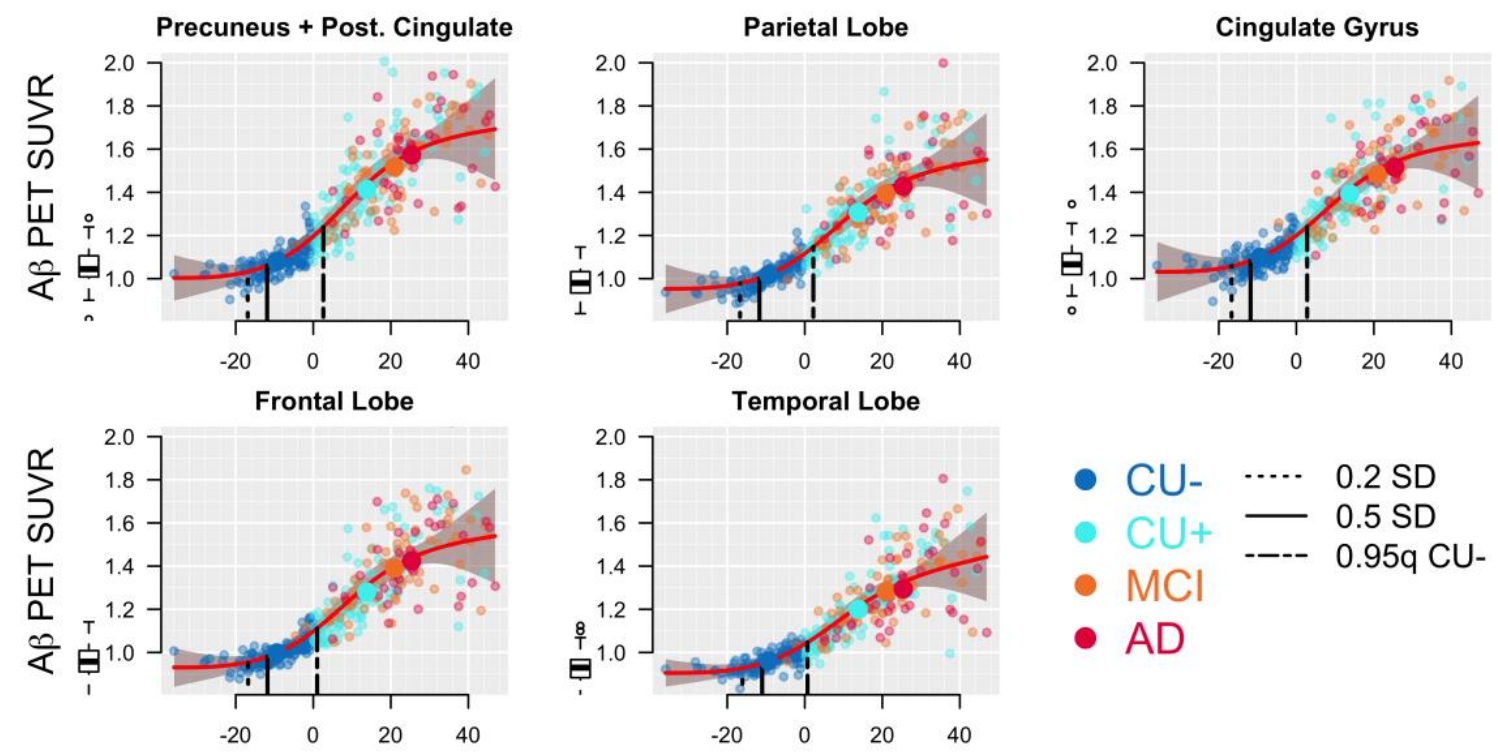

Time From $A \beta+$

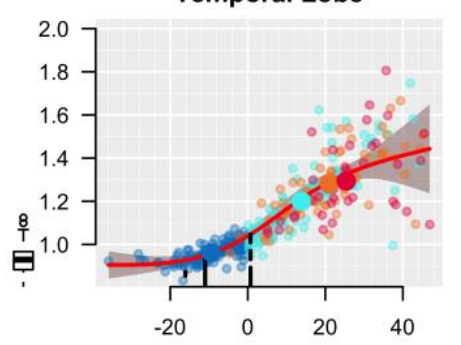

- CU- $\cdots \cdot 0.2$ SD

- $\mathrm{CU}+5 \mathrm{SD}$

- $\mathrm{MCl}$

- AD

Time From $A \beta+$

\section{Effect Sizes of $A \beta$ Increase}

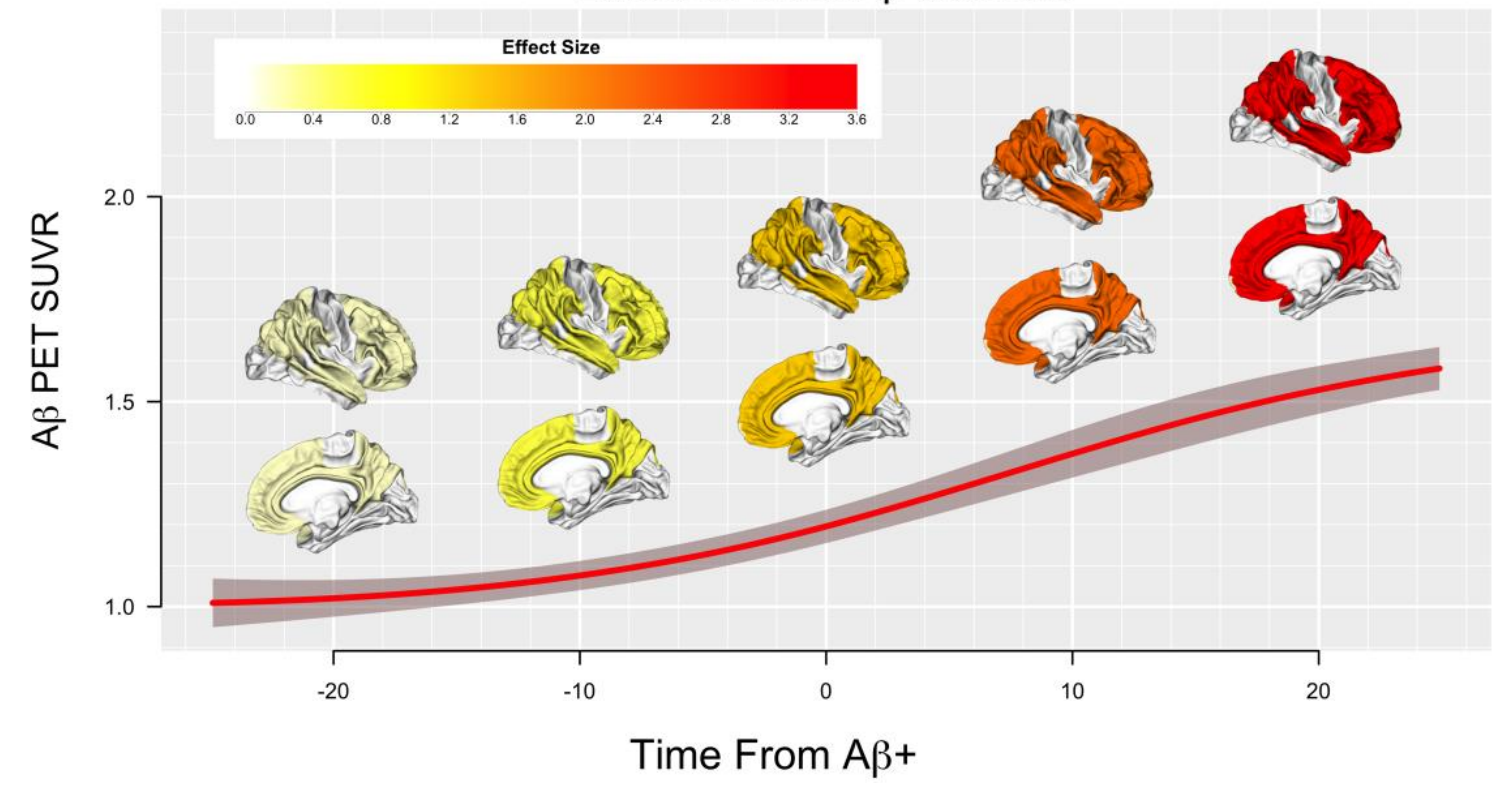




\section{Figure 3. CSF Biomarkers}

CSF biomarker responses are plotted against TFA $\beta+$. Effect sizes, depicting change points are shown as vertical dashed (0.2 SD, initial change) and solid (0.5 SD) lines. Regression curves (red) and corresponding 95\% CIs (shaded grey) are shown. Mean values of the response are plotted against mean TFA $\beta+$ for each of the four diagnosis groups (large symbols). The 0.95 quantile (approximately $1.65 \mathrm{SD}$ if normally distributed) of the response for the CU- group is also shown (short/long dashed line). The boxplots to the left of each figure show the biomarker distribution in subjects that were determined not to be on the AD trajectory (including subjects where the model estimated them to become $A \beta+$ over 120 years of age).
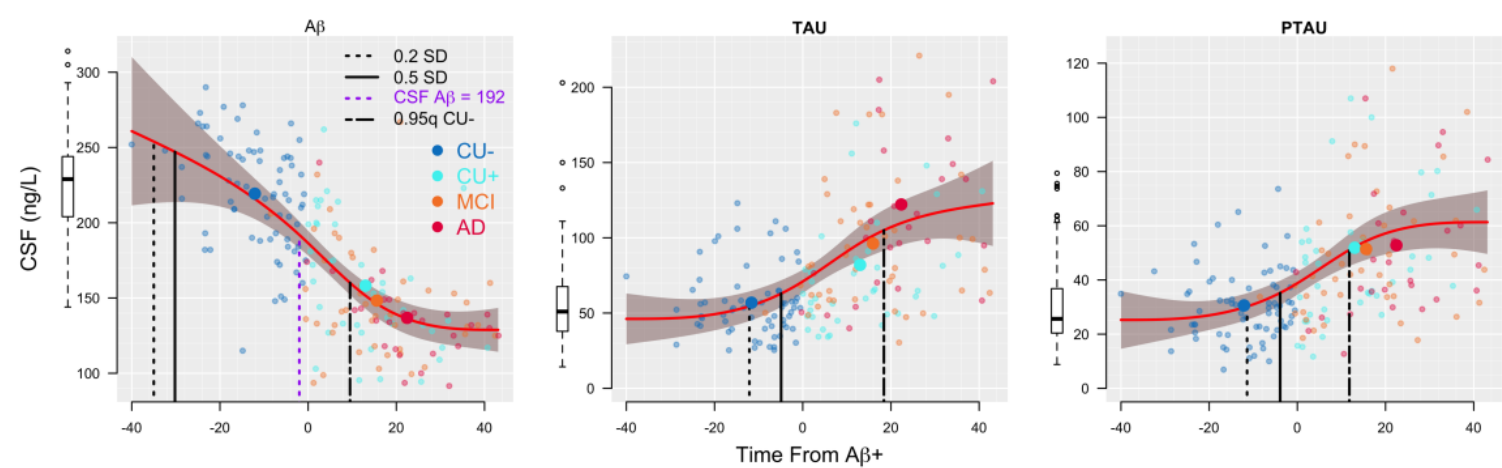


\section{Figure 4. Regional Tau PET}

Tau PET ROIs are plotted against TFA $\beta+$. Effect sizes, depicting change points are shown as vertical dashed (0.2 SD, initial change) and solid (0.5 SD) lines. Regression curves (red) and corresponding 95\% CIs (shaded grey) are shown. Mean values of the response are plotted against mean TFA $\beta+$ for each of the four diagnosis groups (large symbols). The 0.95 quantile (approximately $1.65 \mathrm{SD}$ if normally distributed) of the response for the $\mathrm{CU}$ - group is also shown (short/long dashed line). The boxplots to the left of each figure show the biomarker distribution in subjects that was determined to not be on the AD trajectory (including subjects where the model estimated them to become $\mathrm{A} \beta+$ at over 120 years of age). Effect sizes of tau increase are shown in the bottom panel at TFA $\beta+=-20,-10,0,10$, and 20 years. 
bioRxiv preprint doi: https://doi.org/10.1101/2020.05.18.103226; this version posted May 21, 2020. The copyright holder for this preprint (which was not certified by peer review) is the author/funder, who has granted bioRxiv a license to display the preprint in perpetuity. It is made available under aCC-BY 4.0 International license.
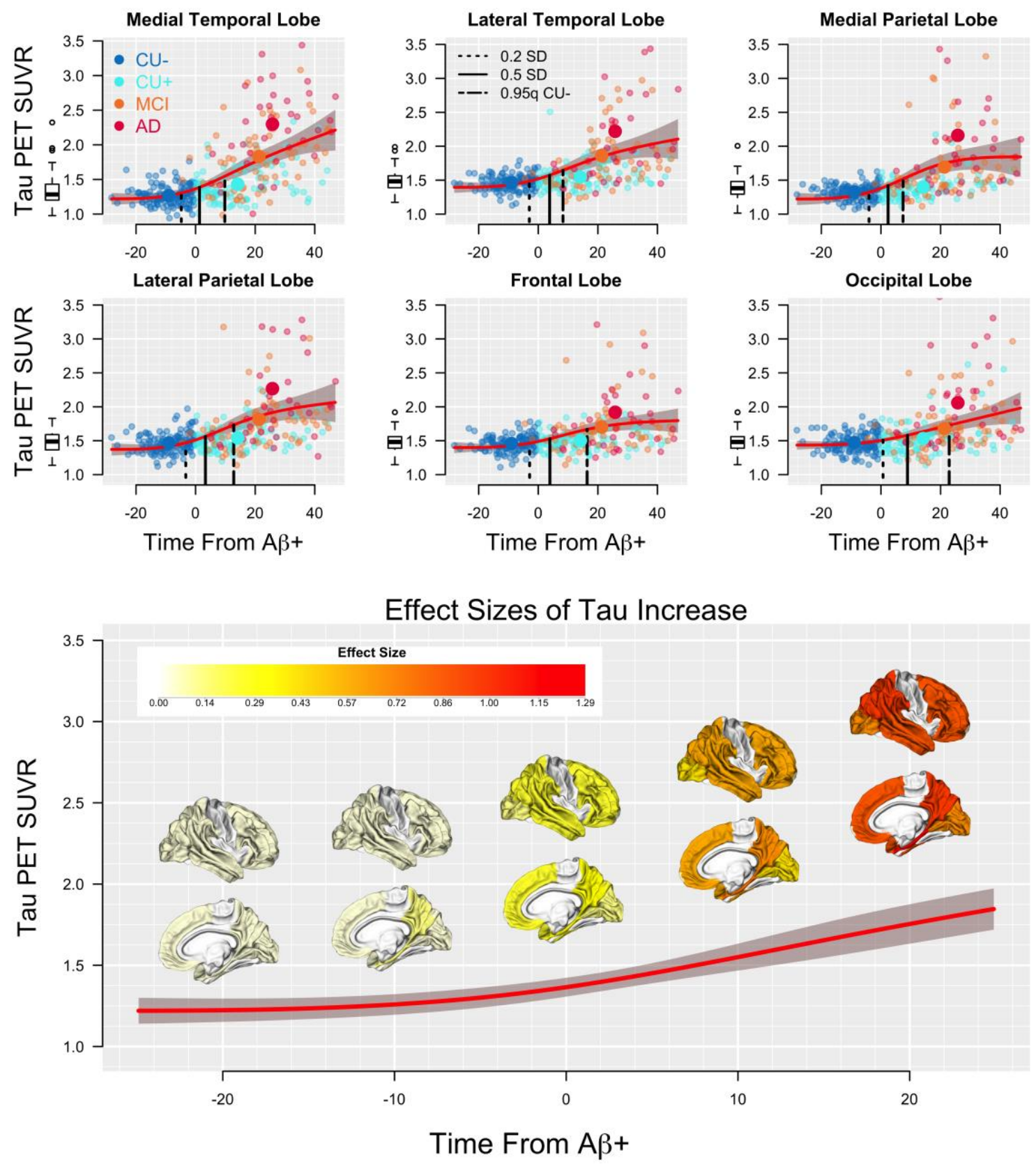


\section{Figure 5. Cognition}

MMSE and PACC scores are plotted against TFA $\beta+$. Effect sizes, depicting change points are shown as vertical dashed (0.2 SD, initial change) and solid (0.5 SD) lines. Regression curves (red) and corresponding 95\% CIs (shaded grey) are shown. Mean values of the response are plotted against mean TFA $\beta+$ for each of the four diagnosis groups (large symbols). The 0.05 quantile (approximately $-1.65 \mathrm{SD}$ if normally distributed) of the response for the CU- group is also shown (short/long dashed line).
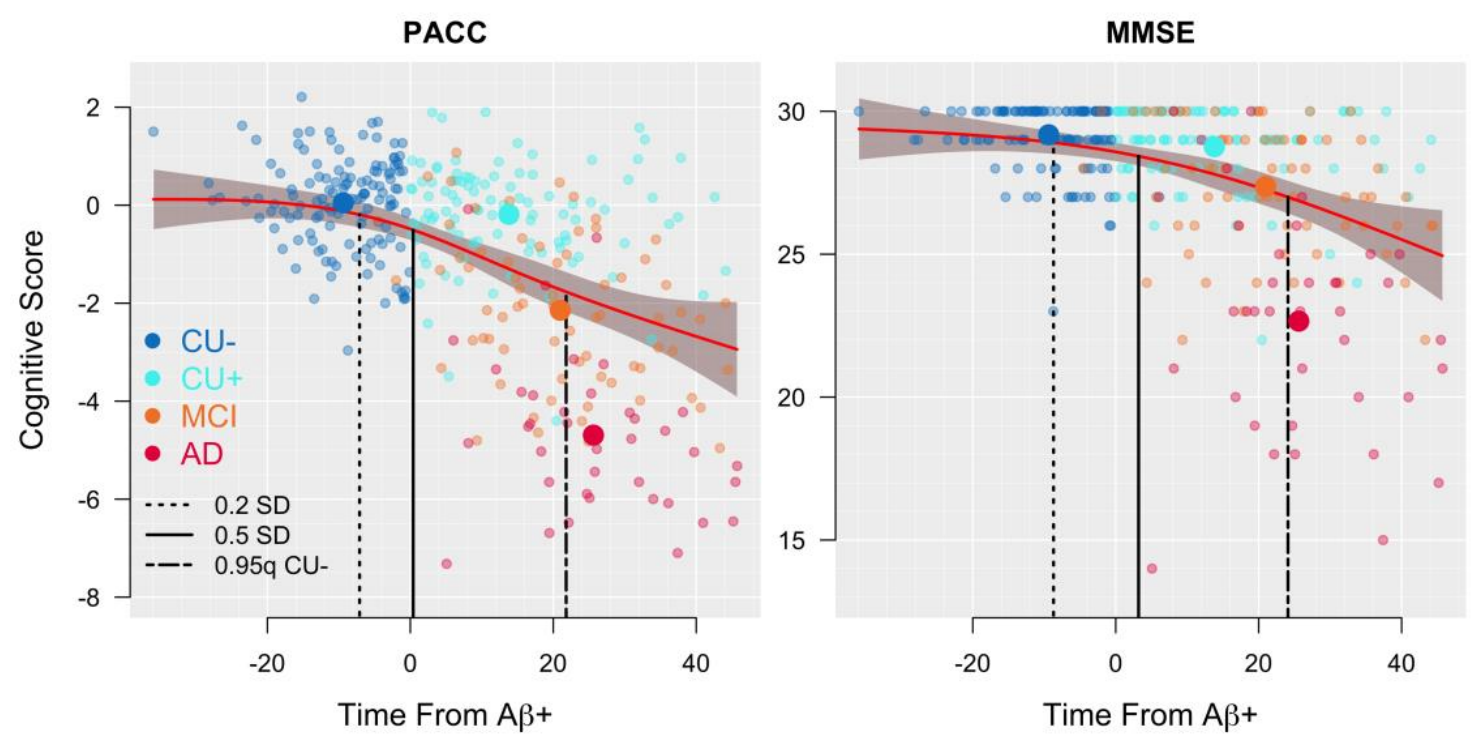


\section{Figure 6. Summary Curves}

Summary curves are shown for all modalities on a scale from zero to one. Responses are scaled such that zero is the least pathological point for each response and one is the mean response in the $\mathrm{AD}$ participants. The initial effect, defined by $0.2 \mathrm{SD}$ change points are plotted.

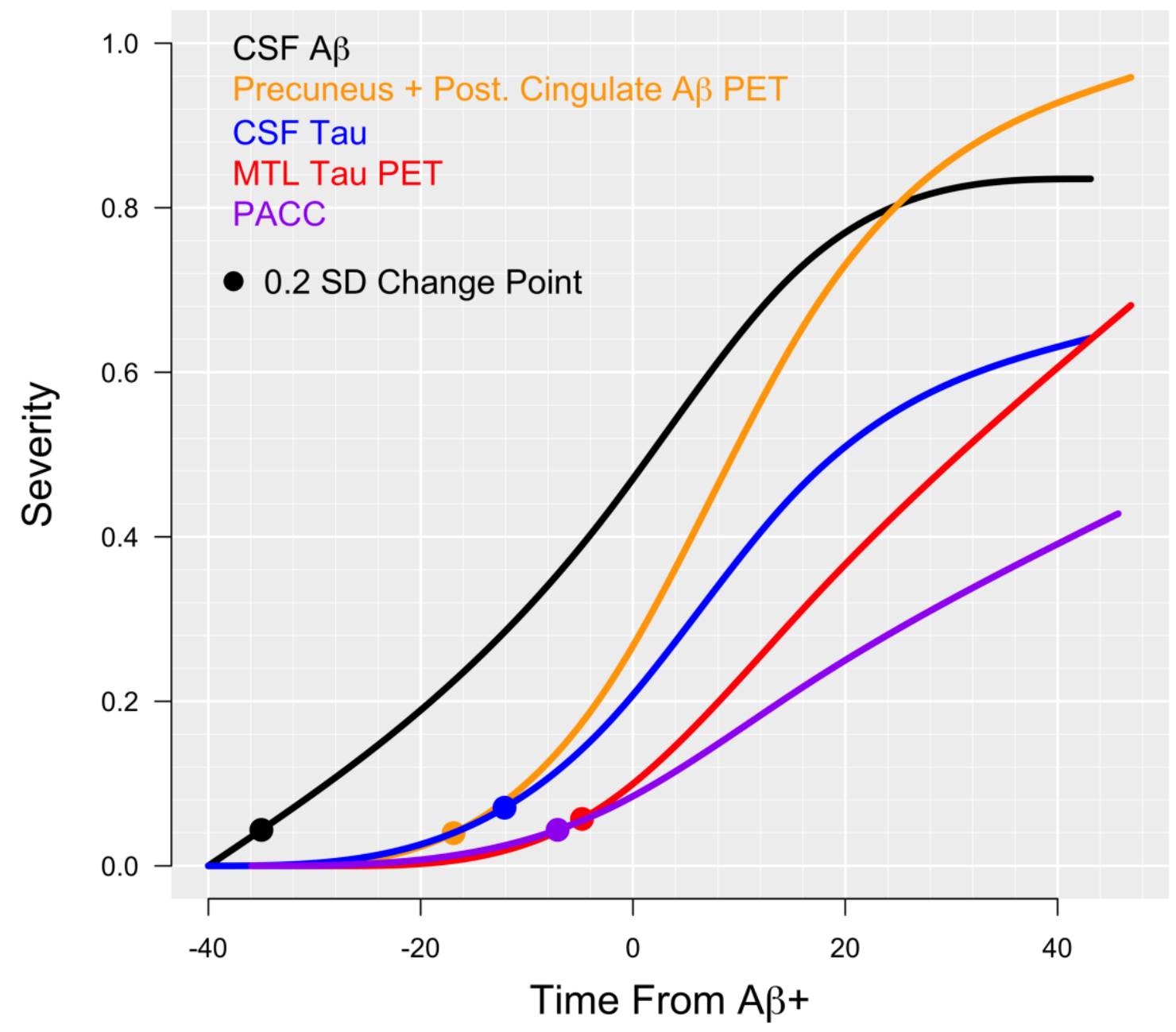


bioRxiv preprint doi: https://doi.org/10.1101/2020.05.18.103226; this version posted May 21, 2020. The copyright holder for this preprint (which

was not certified by peer review) is the author/funder, who has granted bioRxiv a license to display the preprint in perpetuity. It is made available under aCC-BY 4.0 International license.

Table 1. Initial values, effect sizes and change points

\begin{tabular}{|c|c|c|c|c|c|c|}
\hline & $\begin{array}{l}\text { Initial Value } \\
\text { (SD) }\end{array}$ & $\begin{array}{c}\text { Value at } \\
\text { TFA } \beta+=0\end{array}$ & $\begin{array}{c}\text { Difference at } \\
\text { TFA } \beta+=0 \\
\text { (p-value) }\end{array}$ & $95 \% \mathrm{CI}$ & $\begin{array}{c}\text { Effect Size } \\
\text { (Difference } \\
\text { at TFA } \beta+= \\
0 \text { ) }\end{array}$ & $\begin{array}{c}\text { TFA } \beta+ \\
\text { Change Point } \\
(0.2 \text { SD })\end{array}$ \\
\hline \multicolumn{7}{|l|}{$\mathrm{A} \beta$ PET } \\
\hline Precuneus+PC & $1.00(0.14)$ & 1.20 & $0.19(<0.01)$ & 0.09 to 0.30 & 1.35 & -17 \\
\hline Parietal Lobe & $0.95(0.12)$ & 1.12 & $0.16(<0.01)$ & 0.06 to 0.27 & 1.32 & -17 \\
\hline Cingulate Gyrus & $1.03(0.13)$ & 1.20 & $0.17(0.01)$ & 0.04 to 0.30 & 1.32 & -17 \\
\hline Frontal Lobe & $0.93(0.13)$ & 1.10 & $0.17(<0.01)$ & 0.08 to 0.26 & 1.32 & -17 \\
\hline Temporal Lobe & $0.91(0.11)$ & 1.04 & $0.13(<0.01)$ & 0.07 to 0.20 & 1.20 & -16 \\
\hline \multicolumn{7}{|l|}{ CSF } \\
\hline$A \beta$ & $261(34)$ & 186 & $-74(<0.01)$ & -123 to -25 & -2.17 & -35 \\
\hline T-tau & $46(42)$ & 71 & $25(0.01)$ & 7 to 43 & 0.59 & -12 \\
\hline P-tau & $25(25)$ & 39 & $14(0.02)$ & 2 to 25 & 0.55 & -11 \\
\hline \multicolumn{7}{|l|}{ Tau PET } \\
\hline MPL & $1.22(0.49)$ & 1.38 & $0.16(0.02)$ & 0.02 to 0.29 & 0.32 & -4 \\
\hline MTL & $1.22(0.41)$ & 1.37 & $0.15(0.02)$ & 0.03 to 0.26 & 0.35 & -5 \\
\hline LTL & $1.40(0.44)$ & 1.52 & $0.12(0.05)$ & 0.00 to 0.25 & 0.28 & -3 \\
\hline LPL & $1.37(0.47)$ & 1.51 & $0.14(0.04)$ & 0.01 to 0.27 & 0.29 & -3 \\
\hline Frontal Lobe & $1.40(0.33)$ & 1.49 & $0.09(0.13)$ & -0.03 to 0.21 & 0.28 & -3 \\
\hline Occipital Lobe & $1.44(0.36)$ & 1.50 & $0.07(0.13)$ & -0.02 to 0.16 & 0.19 & 1 \\
\hline \multicolumn{7}{|l|}{ Cognition } \\
\hline MMSE & $29.4(2.38)$ & 28.6 & $-0.80(0.17)$ & -1.93 to 0.33 & -0.34 & -9 \\
\hline PACC & $0.12(1.56)$ & -0.49 & $-0.61(0.07)$ & -1.25 to 0.04 & -0.39 & -7 \\
\hline
\end{tabular}

